\title{
Assessment, support and care-taking : gerontological social work practices and knowledge
}

\section{Rossi, Eeva}

2018-07-01

Rossi , E , Seppänen , V M \& Outila , M 2018 , ' Assessment, support and care-taking : gerontological social work practices and knowledge ' , Nordic Social Work Research , vol. 8 , no. 2 , pp. 133-145 . https://doi.org/10.1080/2156857X.2016.1269662

http://hdl.handle.net/10138/326274

https://doi.org/10.1080/2156857X.2016.1269662

cc_by_nc

acceptedVersion

Downloaded from Helda, University of Helsinki institutional repository.

This is an electronic reprint of the original article.

This reprint may differ from the original in pagination and typographic detail.

Please cite the original version. 
This is an Accepted Manuscript version of the following article, accepted for publication in Nordic Social Work Research.

Rossi, E., M. Seppänen, and M. Outila. 2018. “Assessment, support and care-taking: gerontological social work practices and knowledge.” Nordic Social Work Research 8 (2): 133145. doi:10.1080/2156857X.2016.1269662.

It is deposited under the terms of the Creative Commons Attribution-NonCommercial License (http://creativecommons.org/licenses/by-nc/4.0/), which permits non-commercial re-use, distribution, and reproduction in any medium, provided the original work is properly cited. 
Assessment, support and care-taking:

Gerontological social work practices and knowledge

\begin{abstract}
The purpose of this article is to identify, analyse and interpret key practices and knowledge in gerontological social work. This article explores social work practices and knowledge in the context of gerontological rehabilitation using data gathered through thematic and dialogical interviews with seven social workers. In those interviews, social workers described their daily work with older adults. Using frame analysis, the data revealed assessment, support and care-taking frames which included many practices. The social work knowledge consist of factual, theoretical, procedural and practical and personal knowledge. Furthermore, clients' personal knowledge is essential in social work practices of every kind. The study findings identify the importance of support and care-taking practices in gerontological rehabilitation, as well as a need for extensive social work knowledge.
\end{abstract}

Keywords: gerontological social work, social work practice, knowledge, frame analysis, rehabilitation 


\section{Introduction}

The purpose of this article is to identify, analyse and interpret key practices and knowledge in gerontological social work in the context of ongoing demographic change in western societies - specifically, the increasing number of older adults. This changing context will impact on social workers' practices and roles and on the purpose of social work (Coleman et al. 2012; Bachman and Gonyea 2012; Carvalho 2014). It is evident that the growing number of older adults will mean a consequent increase in the need for gerontological social work (NaitoChan, Damron-Rodriguez, and Simmons 2005; Damron-Rodriguez and Corley 2003). In the case of Finland, other changes have also directly affected demand for gerontological social work, with the introduction in 2013 of a new law supporting older adults' capacity and the provision of relevant health and social services. This law requires that every municipality must have expertise in gerontological social work. The law also provides for rehabilitation for older adults at municipality level. While this new legislation does not precisely define gerontological social work or rehabilitation practices, there is an implicit requirement for special expertise, including a need for specialized professional activities, based on specialized knowledge and skills.

Despite the growing body of social work research, it can be said that there is a lack of consensus about what social work is and what social workers do, in both academic (Cnaan and Dichter 2008, 278) and public discourse (Naito-Chan, Damron-Rodriguez, and Simmons 2005). The present article focuses on social work practices and the knowledge that underpins those practices. Social work practice is understood here as a performance involving social workers and clients or social workers and other professionals, referring to activities performed by educated 
professional specialists who are experts in social work. Those activities are highly skilled and include a range of techniques and competencies (Trevithick 2008; Fook 2012), as well as performance, 'in which social workers embody or incorporate theory as an element in the interaction' (Payne 2007, 85). The present study focuses on a specific field of social work in a specific context: gerontological social work, referring to work with older adults and defined as a specialized area that connects common social work knowledge and gerontological knowledge (Naujaniene 2007, 38; Nathanson and Tirrito 1998, 8). The task of gerontological social work is to use the methods of social work to enhance the quality of life of older adults and their families, to support older adults' capabilities and to resolve their social problems (e.g. Mellor and Lindeman 1998, Najuaniene 2007). In empirical studies, gerontological social work has been described in terms of roles, in which the gerontological social worker is seen, for example, as resident advocate, care planner, assessor and counsellor, family social worker, transition coordinator (Koenig et al. 2011), context interpreter, educator, supporter and active member of a multiprofessional team (Sanders et al. 2012).

In addition to a concern with older adults and their wellbeing, the practices of gerontological social workers are set in a range of social and organizational contexts that include long term care (Sanders et al. 2012; Naujaniene 2007), hospitals (Fabbre et al. 2011; Kinni 2008) assisted living (Koenig et al. 2011), day care centres and home help settings (Najuaniene 2007). The present article focuses on gerontological social work in the context of rehabilitation. In Finland, most older adults' rehabilitation is conducted in health care settings or in hospitals. Additionally, there are special rehabilitation centres, established to rehabilitate World War II veterans, which are mostly not-for-profit. In the Finnish welfare system, social workers in such organizations have no administrative decision-making rights or power of the kind assigned to 
social workers who work as municipal officials in social care settings. Today, as the youngest veterans are about 90 years old, rehabilitation can be classified as gerontological or geriatric rehabilitation, based on multiprofessional work.

Our assumption here is that, especially in this multiprofessional context, the practices and knowledge of gerontological social work become visible. In examining gerontological social work practices and the knowledge underpinning these practices in the context of rehabilitation, we address two general questions: what kinds of practices do gerontological social workers identify in their work in a rehabilitation context, and what kind of knowledge can be inferred from social workers' descriptions of their work?

\section{Social work practices and knowledge}

Social work practices can be understood as the performances, activities or interventions of social workers, which can be of various types and may be enacted in a number of different fields (Cnaan and Dichter 2008). Empirical studies variously describe gerontological social work practices as including assessment, psychosocial support, advocacy, care planning (Fabbre et al. 2011), emotional support, case management, resource finding, health education (Naito-Chan, Damron-Rodriguez, and Simmons 2005) and psychosocial assessment, guiding, service planning and case management (Bonifas, Gammonley, and Kelsey 2012). This long list makes explicit the idea that social work practices can be seen as contextual and provisional (Payne 2007). As Payne describes it, "What social workers do, and how they interact with others, is flexible and variable, because it reflects human and social variability, and the people involved, both practitioners and clients will not accept anything else.' (2007, 94). 
Despite this wide variety of social work practices, some common traits can be identified, which can be understood as representing typical gerontological social work practices. These include conventions or standards informing the actions of social workers, as well as a shared agreement about reasonable and appropriate ways of acting (Payne 2007). As understood here, shared agreement relates to ideas about the habitualization and institutionalization of actions (Berger and Luckman 1980, 50-51). This means that some actions have been so frequently repeated as to become a pattern or commonly accepted way of interacting and working that is known to all participants in that practice. For example, in gerontological social work, when an older adult comes to a social work office or rehabilitation centre and meets a social worker, they do not need to define this as a new situation, especially if they have met before. As Goffman $(1986,8)$ put it, when asked 'What is it that's going on here', they can respond on the basis of their earlier experiences and principles of organization that govern events. Goffman used the concept of frame to describe these principles of organizations. Frames can also be understood as 'shared ways of understanding and interpreting different situations' (Virkki et al. 2015, 8); through framing, actors can define situations and understand how they should act.

Appropriate ways of acting in different situations entail a special kind of knowledge, known as role-specific knowledge (Payne 2007, 92; Berger and Luckman 1980, 67-74). Knowledge is central to social work practices, and the relation between professional practice and knowledge has been discussed for decades (e.g. Osmond and O'Connor 2006; Harris et al. 2015; Pohjola and Korhonen 2014). Knowledge, then, is seen as one of the instruments of social work practice, but there are different kinds of knowledge that may be used in the different phases of an interaction (Payne 2007). For present purposes, we are interested in how these different kinds of knowledge can be found in practitioners' descriptions of their work. 
Knowledge of social work has been classified in a number of ways (e.g. Trevithick 2008; Drury-Hudson 1999; Osmond 2005), but all such classifications include in some form i) theoretical, ii) factual or empirical and iii) personal or practical knowledge. Theoretical knowledge explains phenomena, situations, events and the world around us (Trevithick 2008; Drury-Hudson 1999); factual knowledge (Trevithick 2008) or empirical knowledge (DruryHudson 1999) refers to objective knowledge (for example, from empirical research or official statistics; and personal (Drury-Hudson 1999; Trevithick 2008) or practical knowledge (Trevithick 2008) includes intuition, cultural knowledge and ethical knowledge and values. This third category of knowledge also includes the practical wisdom gained from social work practice and formed in the process of working on multiple cases involving similar problems (DruryHudson 1999). In thinking of social work as a context-related activity, procedural knowledge (referring to contextual knowledge and the organizational, legislative and policy context; [Osmond 2005]) becomes an essential element.

However, it should be noted that cultural beliefs and norms shape how we perceive and value certain types of knowledge. Shove et al. (2012) emphasize that in different practices there are three key elements: meanings (cultural beliefs and norms, symbolic meanings, ideas), competencies (knowledge, know-how, skills) and materials (technologies and physical things). These elements interact and are linked together to form practices.

Empirical studies have demonstrated that knowledge can be used both conceptually and instrumentally (Osmond 2006) — that is, one can use knowledge to understand different situations or to guide interventions. In general, conceptual use of knowledge helps to understand the situation, and instrumental use of knowledge is used to guide concrete actions, but these ways of using knowledge are interwoven and interchangeable. In gerontological or geriatric social work, 
research practices and knowledge relate mainly to discussion of competencies and education (e.g. Damron-Rodriguez et al. 2008; Naito-Chan, Damron-Rodriguez, and Simmons 2005) and expertise in gerontological social work (Bonifas, Gammonley, and Kelsey 2012). Naito-Chan, Damron-Rodriguez, and Simmons (2005) suggested that gerontological social workers need a knowledge of geriatrics in order to understand phenomena such as dementia and depression, as well as grief, substance abuse and legal and ethical issues, pointing in particular to the importance of age-specific competencies. Bonifas, Gammonley, and Kelsey (2012) defined social workers' knowledge of gerontology in terms of aging theories, cultural differences, aging problems and psychopharmacology. Fabbre et al. (2011) also mentioned biopsychosocial and ecological models as a theoretical foundation for gerontological social work. In those studies, knowledge was seen as both conceptual and instrumental.

There has also been discussion about how we know (Fook 2012, 41), which can be viewed as relating to the 'source' of knowledge (Hardy and Jobling 2015, 526). In the present article, the concepts of theoretical, factual, procedural or personal knowledge are taken to refer to professionals' knowledge, but it should be noted that, for example, service users' knowledge is also a type or 'source' of knowledge. The 'how' question also asks whose knowledge is valued or privileged in different kinds of situations, connecting the question of knowledge to the question of power (Fook 2012). In the same way, we ask what kinds of knowledge can be discovered from social workers' descriptions and whose knowledge is seen to be valued.

\section{Methods}

The primary aim of this study was to identify, analyse and interpret social workers' practices and knowledge, based on their own descriptions of their everyday work in 
gerontological rehabilitation. In order to find out the workers' emic viewpoint, qualitative research methods were employed. The selection of rehabilitation centres is based on the understanding that in the multiprofessional context, social work becomes more easily explicit, as social workers need to be able to articulate the contribution they can make as well as the added value they bring to an interprofessional team (Ray, Bernard \& Philips 2012, 7), both ow which give the research process an advantage. To this end, we interviewed seven social workers who worked in six rehabilitation centres, focusing on these practitioners' experiences of everyday work with clients.

Participants were found by searching the webpages of Finnish rehabilitation centres. based on knowledge of the rehabilitation system. Social work was mentioned in the webpages of 13 centres, but only six of these included qualified social workers working with older adults. One of the authors contacted those social workers and invited them to participate; all of those contacted accepted this request. All of these social workers had experience of working with older adults, ranging from one to twenty years. They were all qualified social workers according to Finnish regulations, having a Master's degree (or the equivalent) in social work. Interviews were audio recorded and transcribed verbatim. The interviews varied in duration from 90 to 240 minutes, yielding a data corpus of 230 pages of transcribed text in Finnish. The translations were made by the authors during the writing process. These pages were stored in accordance with the principles of research ethics. Part of the research data has been reported earlier as a licentiate thesis written by one of the authors (Rossi 2013).

In the interviews, social workers shared their experiences by describing their meetings with clients and work practices involving clients and multiprofessional teams. Interviews were semi-structured and dialogical. The ideas of the interviews were influenced by ideas of 
Holstein's and Gubrium's (1995) active interview and the Moustakas' (1990, 39-47) dialogical interview. Interviewees were viewed as storytellers, whose descriptions and outlines are based on their experiences, as in social workers' experiences of their work. Both interviewee and interviewer were assumed to be familiar with the phenomena in question and to be actively engaged in constructing meaning (Silverman 2009, 118). Specifically, this means that both interviewee and interviewer (one of the authors) have worked as social workers in a gerontological rehabilitation setting and that both practitioner and researcher were constructing the idea of social work during the interview. Some prepared thematic questions were discussed in the interview, pertaining to social workers, their daily work and functions, social work clients and expertise and multiprofessional working. Participants' knowledge of social work was not explicitly questioned; instead, knowledge was classified by the authors during the subsequent analysis. The interview questions did however ask about the social work expertise, and it might be said that this concept includes the idea of knowledge.

The analytical method was based on Erving Goffman's (1986) idea of frame analysis. According to Goffman (1986, 10-11), frame analysis involves an examination of the organization of experiences and can be used to analyze social interaction. In the present case, the frame or framing refers to social workers' ways of speaking about their work, which may change during the interview. Frame analysis offers a way of understanding, interpreting and analyzing social workers' descriptions of their daily work practices, in which frames were inductively constructed from the participants' descriptions. The analysis also targeted the content of frames but not the relationship or changes between frames.

The analytical process involved four phases, focusing on social workers' descriptions of their work practices with clients and with multiprofessional teams. First, the data as a whole 
were carefully read and summarized, and themes and frames were identified. In the second phase, themes or episodes of the same kind were linked, and the episodes were analyzed to address the questions 'What is talked about?' and 'What is the perspective of the conversation?' Based on the findings in this phase, the relevant frames were identified as assessment, support and care-taking. In the third phase, the contents of frames were analyzed by asking what kinds of practices were talked about. In the final phase, different kinds of work practices and roles within these frames were named. Differences between frames related to different kinds of work practices, roles and relationships among social workers, clients and professionals in multiprofessional teams. Following these analyses of practices, the contents of frames were analyzed again, addressing the questions 'What kind of knowledge can be found?' and 'Whose knowledge is this?' To make the analytical process visible and open to evaluation, representative quotations from interviews are included below. To show the diversity of practices and knowledge, these quotations are presented in three tables, corresponding to the three identified frames. The tables also indicate the different kinds of knowledge inferred.

\section{Findings}

\section{Gerontological social work as assessment, support and care-taking}

In this study, we identified three basic frames for social work practices: assessment, support and care-taking. All of these three frames included two or three different kinds of practices and several kinds of knowledge, which will now be discussed in more detail. Assessment frame: information receiving and gathering and being part of a multiprofessional dialogue 
Assessment has commonly been understood as fundamental to social work processes and rehabilitation (Compton et al. 2005; Fook 2012; Ray and Phillips 2012; Huusko et al. 2000). In the present study, the frame of assessment was linked to practices of information receiving and gathering and being part of a multiprofessional dialogue. In these practices, knowledge was connected with knowledge collection, sharing and construction (Pohjola \& Korhonen 2015, 35). Assessment can be understood as the first phase of the social work process, referring to the social worker's assessment of a client's situation and to their assessment of information received. When social workers gather and evaluate information, they are also preparing for active membership of a multiprofessional team.

\section{[INSERT TABLE 1 NEAR HERE]}

First, assessment as receiving information meant that social workers listened to and heard what other professionals had discovered about the client's condition, need for assistance and life situation, relating for instance to housing and family. Other professionals conducted tests such as the MMSE or GDS-15, which are generally considered to be objective; these empirical facts can therefore be described as 'factual knowledge'. Social workers described how they received other professionals' factual knowledge before meeting clients. It might be said that at the beginning of the process the social workers based their work on other professionals' factual knowledge, and that social workers' practice is to listen and gather information. Privileged knowledge is the factual knowledge of other professionals, gathered by questioning, examining and observing clients, informed by their specialized professional knowledge. This may mean that other professionals define the client's situation and, sometimes, the need for social work. Need definition was significant in those centres where the social worker met only some clients. The 
descriptions of examinations can also be understood as descriptions of the organization's rules and professionals' tasks.

The second kind of assessment was information gathering, conducted by interviewing clients, principally to hear clients' life situations, experiences and life values in the clients' own words. We would argue that this kind of thinking makes explicit the holistic or ecological model on which social work is based, which differs from the disease-centered medical model (Fabbre et al. 2011). Respect for clients' experiences and thoughts can be seen as respect for clients' knowledge, which might be characterized as 'everyday' or 'experiential' knowledge. At these meetings, the client's knowledge is important. When a social worker (e.g. SW1) notes the heterogeneity of older adults (e.g Grenier 2012, 142), this description exposes their theoretical gerontological knowledge or framework.

At the same time, social worker (SW1) emphasized that she must gather some facts about the client's situation, relating for instance to housing, social services and benefits. These 'basic things' can be seen to refer to the social worker's understanding of the task or role of social work in general, which Trevithick (2008) characterized as one kind of theoretical knowledge. The reference to services and benefits can be interpreted as procedural knowledge. Social workers also described their aim as getting to know what is 'really' and 'realistic' (SW1) or 'truly' (SW2) the client's situation.

These words can be seen to refer to an objective type of information and not only to clients' subjective interpretations. Social workers linked the need for objective information to older adults' cognitive skills deficits, requiring that social workers should have gerontological knowledge about such matters in order to properly evaluate clients' descriptions and to understand their abilities and life situation. There might also be a need to compare clients' 
descriptions of their everyday lives with the accounts of others (e.g. relatives, other professionals).

A third kind of assessment was seen as being part of a multiprofessional dialogue, which meant that social workers were active participants in a weekly team meeting and actively engaged with other professionals in their daily work. This finding differs from Kinni (2008), in which social workers were not seen as members of the core rehabilitation team. This may be explained by the different context, as Kinni's research was conducted in a hospital setting while our study was conducted in rehabilitation centres, which involve multiprofessional working, with team meetings as an established practice. Social workers reported that discussion was based on different professional approaches, all of which are needed for a dialogical approach. This kind of practice included knowledge sharing but also knowledge construction (see Pohjola and Korhonen 2014, 35). As SW3 described, social workers and other professionals may differ in their understandings of clients' viewpoints. To be an active member of the team, social workers were seen to need information gained by meeting with clients; in other words, knowledge of a client's situation is based on social workers' observations and interactions with the client (Osmond 2006), as well as on other professionals' factual knowledge. This also means that other professionals are not the only ones with the power to define a client's situations and needs, as social workers also have this power. Additionally, some participants' descriptions made explicit the need for a strong professional identity and negotiation skills, which refers to personal knowledge.

Support frame: listening to life stories, talking together, advising and sharing information

The frame of support involved three work practices: listening to life stories, talking together about clients' life situations and advising and sharing information. Describing social 
workers' practices in terms of supporting their clients indicates that social workers are focused on listening to clients' descriptions of their life stories, situations and needs.

\section{[INSERT TABLE 2 NEAR HERE]}

By listening to life stories, the social workers provided a time and a place for older clients to tell their stories; they were supporting older people by listening them. In this kind of situation, the active agent was the elderly client who had decided to tell his story. The client's knowledge is privileged knowledge, and support practices are based on the client's need.

Sometimes, life stories may be about difficult or even traumatic experiences. Participants noticed that they need to assess their own competencies to work with such clients, requiring the skill to compare their professional knowledge with that of others, and to be reflective. In other words, they need personal metaknowledge. Comparing their work practices with those of other professionals in rehabilitation centres, they argued that they were the only professionals who had time for 'just listening'. This understanding of role differences between professionals can be interpreted as procedural knowledge.

Participants also described life storytelling, saying, for instance, 'these clients would speak as long as two hours' (SW3). We interpret this claim in terms of a conflict encountered by social workers, in which clients need to talk or tell their whole life story but the organization provides limited resources and time for the appointment. Practitioners described the tension between clients' need for support and social workers' time resources. Social workers have to understand both the client's needs and the organization's demands. Understanding both of these things requires gerontological theoretical knowledge and procedural knowledge. In these 
situations, social workers have to make choices: whether to meet the needs of elderly clients or to prioritize the demands of the organization's managers (Fook 2012, 167).

A slightly different kind of support involved thinking together about the client's life situation. To think together meant no one had power over the other; it was more like a shared power. While the client's knowledge about their everyday life was the key aspect of this practice, social workers' procedural knowledge—-for example, knowledge about social services—was also important, and both kinds of knowledge were needed to assess the client's life situation. Social workers' work practices involved active listening and supporting, which differed from 'just listening' in entailing active use of competence and knowledge. However, in this sharing of life situations, the main agent was again the elderly client. It might be said that knowledge is constructed through interaction and the role of client was an active knowledge producer (Pohjola $\&$ Korhonen 2015). Social workers described their practice as providing encouragement in challenging circumstances for clients and their caregivers or family members. The social worker's role could also be seen as a 'context interpreter' (Sanders et al. 2012), meaning in this case that the social worker could help an elderly client to identify alternative options within their current life situation.

The third type of support was education and advice or information provision about social security or service systems; this might equally be called 'informational support', as it refers to the basic practice of information sharing (Compton et al. 2005, 259). Social workers described how clients asked for advice and how clients already knew a little about social services but wanted more specific information or to check certain details. Although clients have knowledge of their own life situation, as well as some procedural knowledge about the service system, that procedural knowledge is not necessarily profound, and the social worker's procedural knowledge 
is therefore needed. Social workers supported and enabled older adults to be the agents of their everyday lives by providing information and giving advice. The need for information and advice provision have increased because the service system has changed at the same time as the clients have become older. It can be difficult for older adults to understand service systems, and they need social workers as interpreters and advisors. SW4 made explicit the social worker's knowledge of Finnish society and its development, as well as their knowledge of aging. Care-taking frame: persuasion and connecting to the service system

The frame of care-taking includes practices of persuasion and connecting clients to the service system. The idea of care-taking includes the requirement of professional responsibility, with connections to care management. Practitioners take responsibility for obtaining help to improve clients' quality of life. Two aspects of care-taking can be seen as a continuum. First, social workers persuade clients, for example, to receive home care services; when the client grants permission, they arrange the services. In this kind of practice, social workers are active agents, and procedural knowledge is especially important. However, in the practice of persuasion, the most important knowledge is the social worker's personal knowledge, which includes internalized knowledge of social work ethics and values.

[INSERT TABLE 3 NEAR HERE]

Persuasion can be seen as a continuum involving assessments and thinking together about life situations. Based on the social worker's assessment as an expert, practitioners saw the client's need for help and became concerned about their life situation. Social workers' practices can be seen as helping clients to understand the available services and their potential benefits. 
Participant SW7 saw a need for homecare services and knew how to obtain them, but the client resisted. This illustrated the need for persuasion, based on the practitioner's knowledge of the client's life situation and procedural knowledge of the social service system. The case also illustrates how the social worker's personal knowledge is gained by working with older clients for several years. Social workers were active in terms of persuading clients to accept homecare services. In this kind of process, the role of the social worker was as the persuader who acted while the client was the target who reacted in a process described as unidirectional. In situations of this kind, the practitioner can be seen as an expert, with professional power over their client.

However, in trying to be active and to enact changes, participants noted the importance of a basic social work value: self-determination. The client could not be forced to accept social services. Although social workers try to help clients to understand the available services and their potential benefits, they can do nothing if the client refuses those services. The practice of persuasion highlighted the importance of knowledge of social work values, requiring personal or practical knowledge that includes an internalized understanding of those values and ethics. Without ethical understanding, persuasion becomes manipulation. Self-determination can be also seen as respect for clients' knowledge and for their power over their own life. Clients are not seen only as care receivers but also as decision-makers.

Social work practice, which was identified as connecting clients to service systems, related to concrete activities carried out by social workers after obtaining permission from the client. Fabbre et al. (2011) called this kind of activity 'tangible support'. Although it can be seen as support, we have used the concept of support in the present study to refer to emotional or psychosocial supports and concrete activities such as helping to complete paperwork, as caretaking. Participants described this practice as working with clients or acting on their behalf. 
Although they worked together, the social worker was the main agent, and practitioners described how they helped, advocated, negotiated and mediated between clients and the social security system.

Social workers described this kind of knowledge and practice as their special expertise within the multiprofessional rehabilitation team. It seems that procedural knowledge is the most valued form of knowledge among social workers. According to Trevithick (2008), this kind of knowledge is essential in medical and nursing practices. It can also be said that this kind of knowledge is quite easy to discern and to differentiate from the knowledge of other professionals. However, social workers also characterized their own organizations as unable to see the importance of care-taking.

Participants reported that they do not have enough time to work with older clients. SW4's quote in Table 3 could also indicate the organization's lack of attention to changes in clients' situations. As clients age, they needed more help, for example, with the instrumental activities of daily living, which means they need more help from social workers to organize services.

Participants' descriptions of a lack of time can be seen in terms of the differing viewpoints of professional social workers and rehabilitation organizations. As in the case of listening to life stories, these are situations where social workers must make choices about whose viewpoints and needs are privileged.

\section{Discussion}

This study has concentrated on questions of social work practices and knowledge in the context of rehabilitation, identifying three basic practices—client assessment, support and care- 
taking — each of which included two or three different kinds of practice and several kinds of knowledge, seen as crossing lines in Figure 1.

\section{[INSERT FIGURE 1 NEAR HERE]}

Figure 1: Practices and knowledge of gerontological social work

While we have studied social work practices specifically in the context of rehabilitation centres, other studies have reported similar practices in assisted living (Koenig et al. 2011), longterm care (Sanders et al. 2012) and medical social work settings (Fabbre et al. 2011). These findings can be understood as explicit descriptions of the institutionalized and shared practices of gerontological social work. On the other hand, some practices (particularly assessment) are informed by the context of multiprofessional rehabilitation. In the present study, social workers pointed out that they are a fundamental element of multiprofessional teams and dialogue in rehabilitation centres. For social workers, working in rehabilitation means working in multiprofessional work settings, where social workers receive and to some extent build their work on the knowledge of other professionals.

However, participants also described some tensions between social workers and rehabilitation organizations in terms of their differing ideas of social work practices. These tensions became especially visible in relation to the support and care-taking frames, which included practices that were less valued by the organization. Social workers described experiences of lack of time, which can be seen as lack of resources. This tension can be understood as indicating a difference of understanding of the task of gerontological social work and rehabilitation. One explanation for the lack of social work resources may be that the 
organization is not fully engaged in the holistic model of rehabilitation but instead favours the idea of gerontological rehabilitation as physical or medical. The importance of cultural norms and values shaping the perception of knowledge becomes visible here. The organizational culture of rehabilitation environments at least partially defines social work practices and knowledge. The present findings highlight the importance of support and care-taking in gerontological social work and rehabilitation, linked to the need for a holistic and psychosocial orientation in working with older adults.

The participating social workers described their special knowledge as procedural, relating to legislation and local social services and to an understanding of the rules of organizations. They used this kind of knowledge instrumentally when, for example, connecting clients to service systems and benefits. This may explain why it proved relatively easy to describe this kind of knowledge, which also distinguishes it from the knowledge of other professionals. Nevertheless, the importance of procedural knowledge suggests a need for contextual understanding, and it is clearly essential for social workers to understand the institutional context in which they (and their clients) practise and live.

The practices discussed here also implied both theoretical knowledge of common social work knowledge (such as the eco-social model and tasks of social work) and gerontological knowledge (such as understanding of aging and abilities of older adults). These kind of knowledge became apparent even if social workers' did not explicitly describe it, confirming that gerontological social work is based both on common social work knowledge and on gerontological (especially social gerontological) knowledge (Najuaniene 2007; Nathanson and Tirrito 1998). It should also be noted that this combination of social work and gerontological knowledge differentiates social workers from other professionals in rehabilitation centres. Some 
form of theoretical gerontological knowledge can be said to be common to all professionals in gerontological rehabilitation settings.

In figure 1, personal knowledge is placed under the other kind of knowledge to describe its essential role for social work practices. Social workers' personal knowledge, also called practical or practice knowledge, includes practitioners' reflexive skills, ethical expertise, internalized values and professional identity. This kind of knowledge was obvious in frame of care-taking but it is included all other frames and practices. When we consider social work as a social activity in a specific setting, it always includes personal, subjective interpretations about that situation, which also clarifies the need for personal knowledge.

As mentioned earlier, there is also discussion about whose knowledge and what kind of knowledge is valued or privileged in different kinds of practice situations (Fook 2012). In this study, we asked what kinds of knowledge can be inferred from social workers' descriptions, with only passing reference to whose knowledge is valued. However, it seems that social workers in the context of rehabilitation valued other professional's knowledge and also the knowledge that was shared and constructed in multiprofessional meetings. It should also be noted that there is a need for clients' everyday knowledge in social work practice of every kind. Here, clients' knowledge was considered essential to practices of support. However, as these findings are based on interviews with social workers, they mostly exclude discussion of how knowledge is constructed in discussions between practitioners and clients. This indicates a need for future research on clients' role in knowledge construction.

The present study highlights the need for extensive knowledge of many kinds in gerontological social work, depending both on the institutional setting and on meetings with clients in relation to their specific needs. This research focused on a specific kind of context for 
gerontological social work, which should be remembered when reflecting on the results and their applicability. In the organizational context of our research, the social workers do not carry out practices connected to e.g. decisions about services, unlike the majority of social workers working with older adults. Therefor the psychosocial element was particularly visible in the social workers' descriptions of their work. Another aspect which has to be taken into account is that the interpretations were based on interviews. Other kinds of research material, based on ethnographic studies, for example, would have brought additional aspects and interpretations to the research process. However, we considered it a strength of the study that one of the authors had been working as a social worker in a rehabilitation organization. This brought valuable knowledge to the research process and certainly had implications in the interview situations. During the analysis, special attention was paid to reflecting on the role of pre-knowledge.

These findings indicate a need for future research on conceptual analyses of gerontological social work and on the significance of different settings for work practices. Our study confirms the importance of including support and caretaking in the practices of gerontological social work even if organizations of social work do not see those practices as elementary part of gerontological social work. Emotional support, 'just listening' and caretaking are needed in the effort to improve quality of life when aging as well as to help older adults to stay in their own homes for as long as they wish.

\section{References}


Bachman, S. S., and J. G. Gonyea. 2012. "Improving health care delivery to aging adults with disabilities: Social work with dual eligibles in a climate of health care reform." Journal of Gerontological Social Work 55 (2): 191-207. DOI: 10.1080/01634372.2011.626843

Berger, P. L., and T. Luckmann. 1980. The Social Construction of Reality. A Treatise in the Sociology of Knowledge. New York: Irvington Publishers.

Bonifas, R., D. Gammonley, and S. Kelsey. 2012. “Gerontological Social Workers' Perceived Efficacy for Influencing Client Outcomes.” Journal of Gerontological Social Work 55 (6): 519536. DOI: $10.1080 / 01634372.2012 .690837$

Carvalho, M. I. 2014. "Social work and intervention with older people in Portugal: A critical point of view." European Journal of Social Work 17 (3): 336-352. DOI: $10.1080 / 13691457.2014 .905459$

Cnaan, R. A., and M. E. Dichter. 2008. "Thoughts on the Use of Knowledge in Social Work Practice." Research on Social Work Practice 18 (4): 278-284. DOI:10.1177/1049731506296165

Coleman, S. A., C. J. Cunningham, J. B. Walsh, D. Coakley, J. Harbison, M. Casey, N. Murphy, and N.F. Horgan. 2012. "Outcomes among older people in a post-acute inpatient rehabilitation unit.” Disability \& Rehabilitation 34 (15):1333-1338. DOI: 10.3109/09638288.2011.636136. 
Compton, B. R., B. Galawy, and B. R. Cournoyer. 2005. Social Work Processes. 7th ed. Belmont: Brooks/Cole-Thomson Learning.

Damron-Rodriguez, J., and C. S. Corley. 2003. "Social work education for interdisciplinary practice with older adults and their families." Journal of Gerontological Social Work 39 (1/2): 37 55. DOI: $10.1300 / J 083 v 39 n 01 \_05$

Drury-Hudson, J. 1999. "Decision making in Child Protection: The Use of Theoretical, Empirical and Procedural Knowledge by Novices and Experts and Implications for Fieldwork Placement." British Journal of Social Work 29: 147-169. http://bjsw.oxfordjournals.org/at University of Lapland.fi

Fabbre, V. D., A. S. Buffington, S. J. Altfeld, G. E. Shier, and R. B. Golden. 2011. "Social Work and Transitions of Care: Observations from an Intervention for Older Adults." Journal of Gerontological Social Work 54 (6): 615-626. DOI: 10.1080/01634372.2011.589100

Fook, J. 2012. Social Work. A Critical Approach to Practice. London: Sage Publications.

Goffman, E. 1986. Frame Analysis. An Essay on the Organization of Experience. Boston: Northeastern University Press.

Grenier, A 2012. Transitions and the lifecourse. Challenging the constructions of 'growing old'. Bristol: The Policy Press. University of Bristol. 
Hardy M., and H. Jobling. 2015. "Beyond power/knowledge—developing a framework for understanding knowledge 'flow' in international social work." European Journal of Social Work 18 (4): 525-542. DOI: 10.1080/13691457.2015.1043240

Harris, J., O. Borodkina, E. Brodtkorb, T. Evans, F. Kessl, S. Schnurr, and T. Slettebø. 2015. "International travelling knowledge in social work: An analytical framework." European Journal of Social Work 18 (4): 481-494. DOI: 10.1080/13691457.2014.949633

Holstein, J. A., and J. F. Gubrium. 1995. The Active Interview. Qualitative Research Methods Series Volume 37. Thousand Oaks: Sage University Press.

Huusko, T., P. Karppi, V. Avikainen, H. Kautiainen, and R. Sulkava. 2000. "Randomised, clinically controlled trial of intensive geriatric rehabilitation in patients with hip fracture: Subgroup analysis of patients with dementia." British Medical Journal 321: 1107-1111.

Kinni, R-L. 2008. “Agency in Multiprofessional Work: A Case Study of Rehabilitation of an Older Patient in Hospital Care." Social Work \& Social Sciences Review 13 (3): 25-47. DOI: $10.1921 / 81147$

Koenig, T. L, J. H. Lee, N. L. Fields, and K. R. Macmillan. 2011. "The Role of the Gerontological Social Worker in Assisted Living.” Journal of Gerontological Social Work 54 (5): 494-510. DOI: $10.1080 / 01634372.2011 .576424$ 
Mellor, J. M., and D. Lindeman. 1999. "The Role of the Social Worker in Interdisciplinary Geriatric Teams." Journal of Gerontological Social Work 30 (3-4): 3-7. DOI: 10.1300/J083v30n03_02

Moustakas, C. 1990. Heuristic research: design, methodology, and applications. Newbury Park: Sage.

Naito-Chan, E., J. Damron-Rodriguez, and J. Simmons. 2005. "Identifying Competencies for Geriatric Social Work Practice.” Journal of Gerontological Social Work 43 (4): 59-78. DOI: 10.1300/J083v43n04_05

Nathanson, I. L, and T. T. Tirrito. 1998. Gerontological social work: Theory into practice. New York: Springer.

Naujaniene, R. 2007. Social Construction of Entering Clienthood in Gerontological Social Work. Acta Universitatis Lappponiensis 130. Rovaniemi: Lapland University Press.

Osmond, J. 2005. “The Knowledge Spectrum: A Framework for Teaching Knowledge and its Use in Social work Practice.” British Journal of Social Work 35: 881-900. DOI: 10.1093/bjsw/bch280.

Osmond, J. 2006. "Knowledge Use in Social Work Practice: Examining its Functional Possibilities.” Journal of Social Work 6: 221-237. DOI:10.1177/1468017306066383 
Osmond, J., and I. O'Connor. 2006. "Use of Theory and Research in Social Work Practice: Implications for Knowledge-Based Practice." Australian Social Work 59 (1): 5-19. DOI: $10.1080 / 03124070500449747$

Payne, M. 2007. “Performing as a ‘wise person' in social work practice.” Practice: Social Work in Action 19 (2): 85-96. DOI: 10.1080/09503150701393577.

Pohjola, P., and S. Korhonen. 2014.'Social Work as Knowledge Work: Knowledge Practices and Multi-professional Collaboration." Nordic Social Work Research 4 (sup 1): 26-43. DOI:10.1080/2156857X.2014.926285

Ray, M., and J. Phillips. 2012. Social Work with Older People. 5th Ed. London: Palgrave Macmillan.

Ray, M., Bernard, M. and J. Phillips. 2009. Critical Issues in Social Work with Older People. London: Palgrave Macmillan.

Rossi, E. 2013 Arviointia, tukea ja huolenpitoa. Tutkimus gerontologisen kuntoutuksen sosiaalityöstä. (Assessment, support and caretaking. Research about social work in gerontological rehabilitation.) Unpublished licentiate thesis. University of Lapland. 
Sanders, S., M. Bern-Klug, J. Specht, P. R. Mobily, and A. Bossen. 2012. "Expanding the Role of Long-Term Social Workers: Assessment and Intervention Related to Urinary Incontinence." Journal of Gerontological Social Work 55 (3): 262-281. DOI: 10.1080/01634372.2011.638702

Shove, E., Panzar, M. and M. Wattson. 2012 The dynamics of social practice. Everyday life and how it changes. London: Sage Publications.

Silverman, D. 2009. Interpreting qualitative data. 3rd ed. London: Sage Publications.

Trevithick, P. 2008. "Revisiting the knowledge base of social work: A Framework for practice." British Journal of Social Work 38: 1212-1237. DOI:10.1093/bjsw/bcm026

Virkki, T., M. Husso, M. Notko, J. Holma, A. Laitila, and M. Mäntysaari. 2015. "Possibilities for Intervention in Domestic Violence: Frame Analysis of Health Care Professionals' Attitudes." Journal of Social Service Research 41 (1): 6-24. DOI:10.1080/01488376.2014.917449. 


\begin{tabular}{|l|}
\hline Frame \\
\hline P \\
r \\
$\mathrm{a}$ \\
$\mathrm{c}$ \\
$\mathrm{t}$ \\
$\mathrm{i}$ \\
$\mathrm{c}$ \\
$\mathrm{e}$ \\
\hline
\end{tabular}

Assessment

- Information receiving

- Information gathering by meeting client

- Multiprofessional dialogue
Support

\section{Care-taking}

- Listening to life stories

- Talking together

- Advising and sharing information
- Persuasion

- Connecting to service system
Theoretical Knowledge: Social work theoretical and gerontological

knowledge nowledge, results

of tests and

observations
Procedural Knowledge: Knowledge about social services and legislation, organizational knowledge
Client's personal Knowledge: clients' values, attitudes, life stories and life situations

Professionals' Practical and personal knowledge

Internalized social work values, professional identity, reflexive skills, knowledge gainded by working experiences 
Table 1. Assessment frame: practices and knowledge

\section{Practice: information receiving}

'...then there is the physician's examination and then PT's and nurse's interview and examinations ... I hear what the physician has found, what others have found out about the home situation and the client's situation' (SW1).

'...other professionals have time to make observations and to tell the social worker about them...' (SW3)

"Nurses can give me information about the client's needs for assistance...' (SW 4).

\section{Practice: information gathering by meeting Knowledge clients}

\section{Knowledge}

Factual knowledge of other professionals: examinations as objective knowledge Clients' mediated knowledge: information about life situation

Procedural knowledge: organization's rules and timetables

\footnotetext{
'...I try to give time to them and really get to know the client's attitude towards life because older adults are all different. Even if you know they all have the same kind of physical condition, they are all different kinds of survivor ... so you have to start from this person's situation and way of thinking and experiences ... I try to find out about the life situation, family situation, housing situation, social services at home, and these kinds of thing, these basic things of social work.' (SW1) '...orientation is a holistic one' (SW6) or 'almost the whole life situation' (SW 7).

'...and $y$ if the client says that he does not want any services, you have to think if it is realistic (...) is he really capable to evaluate the situation or is there need to ponder on the situation with relatives...'
} (SW1).

\section{Practice: being part of multiprofessional Knowledge dialogue}

\footnotetext{
'Many times, clients talk about things and social workers can understand the client's different point of view and then tell their colleagues ... everyone sees things from their own point of view. And that is the way it should be' (SW3).

'...in these multiprofessional meetings ... I can say what I think about the situation, my own viewpoint .... we discuss the client's situation very carefully' (SW4).

'We think about the client's situation, we all express our opinion ... we consider together' (SW6).
}

Social work theoretical knowledge: holistic model of social work, knowledge of tasks of social work Personal knowledge: internalised ethical ideas respecting uniqueness of client Gerontological theoretical knowledge: heterogeneity of older people, knowledge about older adults' abilities and skills Client's everyday knowledge: client's values and attitudes Procedural knowledge: benefits and services
Personal knowledge: metaknowledge as strong professional identity Clients' intermediated knowledge: clients' stories about 'things' Gerontological theoretical knowledge: understanding older clients Social work theoretical knowledge: understanding multiprofessional working 
Table 2. Support frame: practices and knowledge

\begin{tabular}{ll}
\hline Practice: listening to life stories & Knowledge \\
\hline 'being beside him and hearing the life stories' (SW1); & Clients' knowledge: life stories and situation \\
'psychosocial support is a very big part of work, & Gerontological theoretical knowledge: \\
clients have many concerns at home. Many clients & understanding older adults need to tell their \\
feel they can be helped when I just listen to them' & story \\
(SW3). & Social work theoretical knowledge: \\
'....someone is listening and hearing' (SW 5). & knowledge of tasks of social work \\
'...sometimes I feel ... I don't have enough knowhow' & Personal knowledge: metaknowledge as \\
(SW4). & evaluating one's own competencies \\
'...these clients would speak as long as two hours', & \\
(SW3). & Procedural knowledge: organization's rules \\
& and time resources
\end{tabular}

Practice: talking together
'...She was thinking about what she is doing. Is she
doing totally wrong for her husband if she gives up
spouse care? We were talking about the situation and
the different dimensions of the situation ... what kind
of place is this for her husband...' (SW6).

Knowledge

Client's everyday knowledge: client's life situations

Procedural knowledge: benefits and services

Gerontological theoretical knowledge:

understanding spouse and process of giving up

\begin{tabular}{ll}
\hline Practice: advising and sharing information & Knowledge \\
\hline '...client wants to know how to use this service, which & Clients' knowledge: \\
is already allocated to him' (SW2). & Clients' everyday, practical knowledge \\
'...so many little questions about practical things' & $\begin{array}{l}\text { Procedural knowledge: knowledge about } \\
\text { service system }\end{array}$ \\
(SW2). & Theoretical knowledge: societal knowledge \\
'...talking about these service systems and explaining & about development of Finnish society \\
to clients' (SW1). & \\
'Service systems have become fragmented and & \\
complicated' (SW4). & \\
\end{tabular}


Table 3. Care-taking frame: practices and knowledge

\begin{tabular}{ll}
\hline Practice: persuasion & Knowledge \\
\hline '...I have spoken about this for three years. Every & Procedural knowledge: knowing service \\
time the spousal caregiver comes here and she is & systems \\
very tired.... Well, we start again to speak about & Personal knowledge: long experience of \\
these things. Can I call to the social service office & working with same clients; understanding \\
this time to get some homecare services ...' & of client's situation; ethical knowledge \\
(SW7). & and internalized social work values \\
'...get [client] to understand or approve or agree & Client's intermediated knowledge: \\
that it would be better for them if things were & professional knowledge about client's \\
different...' (SW5). & situation \\
'We (professionals) cannot decide that this client & \\
receives home care services' (SW1). & \\
”.... sometimes the client might have unrealistic & \\
expectations and even if you try to speak to him, & \\
he does not listen ... but you cannot force & \\
them...the right to self-determination is so strong, & \\
that we have to respect it as far as possible...” & \\
(SW4)
\end{tabular}

\section{Practice: connecting clients to service system Knowledge}

\footnotetext{
'...helping, filling out applications for benefits and, of course, to order services. In my work, it means acting on their behalf. Because these war veterans are so old, they can't fill out applications by themselves, so it's not actually helping, it's acting on their behalf...sometimes I'd like to really engage in a client's situation and have more work time for that. Sometimes I have to do it because the client doesn't have any close relatives and so I have to find out the situation. I can't leave him without help. Sometimes I feel our chief does not understand the situation' (SW 4).
}

Procedural knowledge: knowledge about legislation and local service system and benefits; organizational knowledge about organization's rules

Gerontological theoretical knowledge: understanding the aging process and abilities of older adults 